out by unskilled porsonnel after perhaps half an hour's training in the routine. Further, as the liquid used is self-regenerating and waste is reduced to the absolute minimum, the cost of the process is moderate; an example given was the case of a production run of 1,600 articles each having a superficial area of $2 \cdot 1$ sq. ft., in which the operating cost, including energy, drag-out losses and labour at standard rates, was $0.08 d$. per sq. $\mathrm{ft}$. The makers of the plant are High Grade Metal Tests, Ltd., 24 Marshalsea Road, London, S.E.1.

\section{Subnormal Factors in Human Personality}

In his presidential address before the Section of Psychology and Educational Science at the thirtieth Indian Science Congress at Calcutta in January 1943, Dr. B. L. Atreya spoke on the "Supernormal Factors in Human Personality". In a rapid review of his chosen field, Dr. Atreya sketched in broad outline the history of the subject as it was known in the West and pointed out the work that had been done since the early days of the Society for Psychical Research, when investigation was hindered by lack of means and by the slight development of those statistical methods whereby results might be quantitatively analysed.

Although Dr. Atreya appears not to have seen fit carefully to distinguish the wheat grains from the mountain of tares, his outline of the mass of material will perhaps fulfil the purpose of dissuading future students from tackling the subject unless they are prepared, not only to face some of the most formidable of psycho-philosophical questions, but also to make themselves acquainted with almost the whole range of studies dealing with the psychology of deception, testimony and so on. Competent investigators are rare and urgently wanted, and it is to be hoped that Dr. Atreya's address will stimulate Oriental students to apply Western methods to the abundant material available in their own lands.

\section{Prawn Fisheries of India}

DR. B. ChOPRA, in his presidential address to the thirtieth Indian Science Congress, Calcutta, 1943, has gathered together interesting information concerning the various Indian prawns of economic importance and their fisheries. There are many species of edible prawns in India, the most important and largest being the so-called sea-prawns or Penæids. These apparently breed in the sea, the young migrating to the lower salinities of backwaters, lagoons and estuaries to return again at maturity to the sea to hatch their eggs. Among the freshwater prawns the members of the Palæmonidæ occur in enormous numbers with extensive migrations from fresh to brackish waters, presumably for breeding. The tiny Sergestid Acetes, rarely more than an inch in length, makes up for its small size by its abundance and occurs in estuaries and backwaters, but rarely penetrates beyond tidal influence. Not a single complete life-history of any of these prawns is known, and there is here a great opportunity for research which should yield good results. Methods of fishing and curing are mostly very primitive although in certain parts, notably Madras, much progress has been made in improving methods, gear and boats. More research is necessary in every direction, and Dr. Chopra's address indicates the special needs of the industry.

\section{Folk-Lore of Epilepsy}

IN a recent paper on this subject (Med. Press and Circ., 1, 154; 1943). Dr. J. D. Rolleston directs attention to the large number of synonyms for epilepsy, many of which are popular terms, alike in Ancient Rome, the Middle Ages, and Bavaria in recent times. The English term 'falling evil' or 'falling sickness', which corresponded to the Latin morbus caducus, was for a long time prevalent but has now become obsolete. The chief folk-lore cause for epilepsy, which is still held by primitive races, was demoniac possession. Many examples of this belief have been found not only in the ancient Babylonian and Assyrian texts and the literature of ancient Greece and Rome, the Bible and the Talmud, but also in the West Indies, West Africa, Patagonia, Siberia, India, Ceylon, China and elsewhere (Tylor and Frazer). Another factor in the folk-lore causation of epilepsy was an astrological origin and the moon in particular. Moreover, the state of the moon was responsible in popular estimation not only for the occurrence of epilepsy but also for the efficiency of treatment.

As regards prophylaxis of epilepsy, in accordance with the rule in medical folk-lore, preventive methods in epilepsy were much rarer than curative treatment, and can be classified into external and internal applications derived from animals or plants. Treatment consisted in remedies of human origin such as blood, umbilical cord or placenta by mouth. Animal remedies took the form of their flesh, -blood, milk, rennet, bile, lung, urine, testes or dung and were administered most frequently by mouth, but were sometimes made up into a plaster, liniment or amulet; plant remedies consisted of mistletoe, elder and roots and seeds of the pæony, and mineral cures were represented by precious stones, silver coins and lead. There are numerous examples on record of the supposed transfer of epilepsy to other persons, animals or plants. Other methods of treatment were charms, invocation of patron saints and miscellaneous cures, which included mock burial, castigation of the patient to drive out the supposed evil spirit, venesection and inhalation of tobacco smoke.

\section{Simplified Subscribers' Telephone Sets}

An article by E. S. MeLarn (Elect. Comm., 21, No. 1 ; 1942) describes designs which represent the first successful attempt at evolving a type of subscriber telephone set in which the components are designed and co-ordinated logically with the view of achieving simplified installation, maximum reliability and economy in maintenance. The improvements resulted from lengthy and intensive study of subscriber set behaviour in the International Telephone and Telegraph Associate Telephone Companies, operating under the most diverse conditions. Maintenance cost could be lowered if repairs were reduced to a simplified error-proof mechanical operation, for less skilful help would be required and the training period curtailed. An analysis of telephone set troubles under all kinds of climatic conditions shows that the causes are due principally to $(a)$, excess moisture, dirt, lint and insects, and $(b)$, open- and high-resistance circuits brought about by deteriorated soldered joints, broken conductors and poor contact between conductors and screw-heads.

The improved features of the new telephone sets introduced as a result of the investigation may be summarized as follows : complete unit mounting of 
components; no loose wiring; screw connexions throughout and absence of soldering; gravity switch a single unit, and integral with the base assembly, being readily accessible for adjustment; dial mechanism and gravity switch springs protected from dust, lint, insects, etc. ; all spring contacts doubleconnected in parallel; gravity switch springs operated by a bronze roller; simplified tamperproof ringer ; induction coil and condenser sealed in bakelite cases; cellulose acetate sheet and plastics used instead of paper, fibre and textile insulation; new tipless cord which is easier to connect, prevents error, is more durable, snarl-resistant, and cheaper to use ; components of entire set replaceable with a screwdriver by unskilled repair men and impossible to assemble incorrectly; rust-resisting steel base plate of sufficient thickness to prevent thread stripping.

\section{Electrical Installations in Hospitals}

A PAPER on this subject read recently in London by $F$. Charles Raphael before the Institution of Electrical Engineers reviews the considerations which apply more particularly to hospitals than to other public buildings. For permanent work, paper-lead cable is recommended for the circuits to the fuseboards and wiring in conduit for the sub-circuits. Under-floor ducts are not recommended for hospital wiring. Suggestions are made regarding the selection of accessories and fittings. For general ward lighting a comparatively low value of horizontal illumination is recommended, with local lighting at the beds. Capacitance dimming is described, the future use of fluorescent lamps is discussed, and the shadowless lamp for operating-table lighting is described. Precautions to be taken against explosions in operating theatres are referred to and the requirements for screening in connexion with high-frequency (diathermy) apparatus necessitated by war conditions are reviewed, the opinion being expressed that regulations for this will be continued after the War. The precautions necessary in the construction and use of apparatus for electric therapy are discussed, developments in X-ray apparatus are dealt with and questions of voltage-drop and shielding are briefly mentioned. On ultra-violet treatment, the opinion is expressed that the mercury lamp, possibly supplemented by ordinary tungsten filament lamps, should eventually entirely displace the more expensive arclamp treatment and that there is no need to aim at an artificial reproduction of sunlight. Other subjects which are dealt with briefly are infra-red rays, cardiograph wiring, heating, ventilation of operating theatres, water supply pumps, cooking, refrigeration, lifts and signalling circuits.

\section{Tuberculosis in Peru}

The following results as to the incidence of tuberculosis in Peru were recently obtained by Dr. Ricardo Martinez of Lima (J.Amer. Med. Assoc., Oct. 24). A positive index to tuberculin was found in 68.45 per cent of conscripts, 65 per cent in school children of the Callao province, 77.98 per cent among the applicants for entrance to the University of Lima, and 95 per cent in the various groups of teachers and unions of workers. The proportion of positive reactions to tuberculin in conscripts from coastal areas was 74.64 per cent, 58.43 in those from the mountains and 75 per cent in those from wooded regions. The positive results to tuberculin are higher in Peru than in the Argentine, Brazil, Paraguay and Uruguay, and less than in Cuba and Venezuela. X-ray examinations of school children show that active tuberculosis increased from $4 \cdot 1$ per cent in 1938 to $5 \cdot 3$ per cent in 1941.

\section{Bibliography on Management and Labour}

THE Sheffield City Libraries have issued as Research Bulletin No. 7 a select bibliography on management and labour. This covers approximately the period 1932-42, the periodical references being, however, limited mainly to periodicals which are available in the Commercial and Science and Technology Libraries at Sheffield. Books not easily consulted or obtained have also been excluded, but some older classic books have been included, such as F. W. Taylor's "The Principles of Scientific Management". These limitations somewhat diminish the value of an other. wise excellent compilation, for there are a number of excellent modern books such as T. N. Whitehead's "Leadership in a Free Society", C. I. Barnard's "The Functions of the Executive", F. J. Roethlisberger's "Management and Morale" which cannot be excluded on these grounds, and the omission of reference to any of the works describing the important investigations initiated by Elton. Mayo at the Western Electric Co. is a serious defect. References to readily accessible pamphlet literature, especially that issued in Great Britain during the War, are also incomplete. Owing to the paper shortage, copies cannot be supplied to individual students, but are available to firms and research organizations on official application, with which $3 d$. should be enclosed to cover postage.

\section{Announcements}

Prof. A. C. Chrbnall, professor of biochemistry in the Imperial College of Science and Technology, has been appointed Sir William Dunn professor' of biochemistry in the University of Cambridge, in succession to Sir Frederick Gowland Hopkins (see Nature, April 10, p. 415).

DR. E. D. Hughes, lecturer in chemistry at University College, London, has been appointed professor of chemistry at the University College of North Wales, Bangor.

The following appointments and promotions have recently been made in the Colonial Service: P. C. Owen, assistant conservator of forests, Sierra Leone ; J. S. Webb, mineralogist, Nigeria ; R. A. Hutchinson, veterinary officer, Gambia; N. V. Rounce, district agricultural officer, Tanganyika Territory, to be senior agricultural officer, Tanganyika Territory.

The Academia Nacional de Medicina of Buenos Aires has recently established the Hirsch Medical Scholarship with a fund of 500,000 pesos (about $£ 30,000$ ) given by $\mathrm{Mr}$. Alfredo Hirsch, of Buenos Aires. Selected students will follow medical studies in the United States or Great Britain for two years, beginning in the middle of 1943. For the first ten years the scholarships will be given for studies on cancer, leprosy and infantile paralysis.

ERratum. In the article in Nature of May 1 on "Cultivation of the Douglas Fir in Great Britain", on p. 493 , col. 1, line 17 , the word "and" is superfluous ; Pseudotsuga Douglasii and Ps. taxifolia are alternative names for the same tree. 